\title{
The Opportunities and Challenges of an Interdisciplinary Clinic
}

\author{
Paula Galowitz
}

\section{Introduction}

Law school clinics in many countries increasingly provide the major opportunities that law students have to engage in interdisciplinary collaborations with other professionals. ${ }^{1}$ The collaboration may be with a wide range of professionals, such as: doctors and medical students; social workers and social work students; business school students; engineering faculty and students including biomedical engineering students; nursing students; and experts in public health, education, mental health or palliative care. ${ }^{2}$ It can occur in diverse contexts or targeted to specific populations, such as children, the elderly, victims of domestic violence or low-income business owners.

Some examples of these interdisciplinary clinics illustrate their variety. Clinical legal education initiatives in South Africa, Thailand and Ukraine promoted public health through programs that partnered with the Law and Health Initiative of the Open Society Institute's Public Health

1 One of the ways in which the practice of law, including public interest law, is changing in this century is the increased focus on interdisciplinary and collaborative lawyering. See Karen Tokarz et al., Conversations on "Community Lawyering": The Newest (Oldest) Wave in Clinical Legal Education, 28 Wash. U. J.L. \& Policy 359, $362(2008)$.

2 Although beyond the scope of this article, the literature on interdisciplinary higher education generally is insightful and has implications for legal education. See, e.g., Elisabeth J. H. Spelt et al., Teaching and Learning in Interdisciplinary Higher Education: A Systematic Review, 21 Educational Psychology Review 365 (2009), available at http://www.springerlink.com/content/k737068167hl2007/fulltext.pdf;

Martin Davies and Marcia Devlin, Interdisciplinary higher education: Implications for teaching and learning (Centre for the Study of Higher Education, The University of Melbourne, 2007) available at http://www.cshe.unimelb. edu.au/resources_teach/curriculum_design/docs/InterdisciplinaryHEd.pdf

Information about interdisciplinary models of service learning in higher education is available at the National Service-Learning Clearinghouse at http://www.servicelearning.org/instant_info/fact_sheets/he_facts/ interdisciplinary (last visited on June 3, 2012). 
Programs. ${ }^{3}$ In South Africa, palliative care was integrated with legal services; law students worked with staff at a hospice association to conduct workshops on wills, debts and family law for hospice caregivers. ${ }^{4}$ In Ukraine a Medical Law Clinic was started to advise and represent clients; in Thailand a law clinic wrote an HIV/AIDS Community Legal Education Manual, collaborated with organizations working on health and human rights issues to discuss harm reduction and incarceration, and implemented community education programs in prisons, detention centers and community centers. ${ }^{5}$ At Palacky University in the Czech Republic a new Patient's Rights Legal Clinic, which prepares students to give legal advice, is taught by lecturers of the medical faculty and lawyers from a human rights non-profit. ${ }^{6}$ A clinic in the United States provides business planning and legal advice to small businesses; law and business students collaborate to assist with community economic development. ${ }^{7}$ Another United States clinic combines students in law, business, medicine, social work, biomedical engineering, and arts and sciences in a collaboration focused on intellectual property and business formation, with an emphasis on biodiversity and agricultural-biotechnology innovations. ${ }^{8}$

These clinics teach students to represent clients effectively and offer the possibility to advance social justice. The nature of these collaborations varies considerably, from the kinds of professionals that collaborate to the nature of the populations served..$^{9}$ They provide an opportunity for a range of services beyond the representation of individual clients. The interdisciplinary clinics also create

3 For a discussion of these clinical legal education initiatives, see Tamar Ezer et al., Promoting Public Health through Clinical Legal Education: Initiatives in South Africa, Thailand and Ukraine, 17 Human Rights Brief 27 (2010). The objectives of these programs "range from legal empowerment of marginalized communities to client-centered services to norm-setting and policy advocacy. This diversity reveals the variety of methods through which law and health partnerships can improve global public health." Id.

4 Id.

5 Id. at 27-28.

6 A description of the Patient's Rights Legal Clinic at Palacky University can be found at http://en.wikipedia.org/wiki/ Centre_for_Clinical_Legal_Education_\%28Palack\%C3\%BD_University,_Faculty_of_Law\%29\#Patient.27s_ Rights_Legal_Clinic (last visited May 17, 2012). In addition, an interprofessional medico-legal problem-cased learning program was developed for medical students and students of law at Palacky University. See http://oto. sagepub.com/content/143/1_suppl/124.1.full

7 See Susan Jones, Promoting Social and Economic Justice through Interdisciplinary Work in Transactional Law, 14 Wash. U. J.L. \& Policy 249 (2004).

8 The Intellectual Property and Business Formation Clinic at Washington University in St. Louis is described in the article by Anthony J. Luppino, Minding More Than Our Own Business: Educating Entrepreneurial Lawyers Through Law School-Business School Collaborations, 30 W. New Eng. L. Rev. 151 (2007).

9 There are many articles that discuss these collaborations and aspects of these collaborations. For example, see Karen L. Tokarz, Introduction to Poverty, Justice, and Community Lawyering: Interdisciplinary and Clinical Perspectives, 20 Wash. U. J.L. \& Pol'y 1 (2006) (series of conferences and scholarship on the "practical, pedagogical, ethical, and social justice aspects of interdisciplinary clinical teaching and practice"), Id. at 2; Alexis Anderson, Lynn Barenberg and Paul Tremblay, Professional Ethics in Interdisciplinary Collaboratives: Zeal, Paternalism and Mandated Reporting, 13 Clinical L. Rev. 659 (2007) (ethical issues in collaborations between lawyers and social workers); Rose Voyvodic and Mary Medcalf, Advancing Social Justice Through an Interdisciplinary Approach to Clinical Legal Education: The Case of Legal Assistance of Windsor, 14 Wash. U. J.L.\& Pol'y 101 (2004); Dina Schlossberg, An Examination of Transactional Law Clinics and Interdisciplinary Education, 11 Wash. U. J.L.\& Pol'y 195, 203 (2003). 
linkages between schools within the university and initiatives for outreach to the community. ${ }^{10}$ Each of the professions in an interdisciplinary collaboration has its own culture, values and definitions of roles that impact effective collaboration. Exposing students to these different professional cultures can create opportunities for improved, more complete service for our clients, and for students to develop into more reflective practitioners as they use the other professions' approaches as a mirror to deepen reflections on their own professional role. The clinics also provide opportunities for clients/patients to be part of the collaborative team. Among the cultural challenges are conflicts around differing views of responsibilities to the client, duties of confidentiality, and what constitutes a conflict of interest.

This article focuses on one such collaboration: the Medical-Legal Advocacy Clinic, a medicallegal partnership in a law school clinic, in which law students and medical providers collaborated to address health care issues more effectively. That clinic, which I co-teach, is a medical-legal partnership with a multidisciplinary and holistic approach to provide legal advocacy in a medical setting for clients referred by medical professionals. The model of medical-legal partnerships is used in this article to examine the opportunities and challenges of interdisciplinary clinics for students, clients and faculty, and to provide a way to reflect critically on interdisciplinary clinics generally. In Section I, definitions of interdisciplinary clinics are discussed along with exploring reasons for their growth. Section II describes the attributes of and models for these clinics. The Medical-Legal Advocacy Clinic at New York University School of Law is discussed in Section III. Section IV addresses the opportunities of interdisciplinary clinics for students, clients and the faculty. Section V discusses the challenges of these clinics, including suggestions to address some of the challenges and enhance the opportunities of interdisciplinary clinics.

\section{Definitions of Interdisciplinary Clinics and Reasons for Their Growth ${ }^{11}$}

Typically, an interdisciplinary ${ }^{12}$ clinic is collaboration between or among law students and other students in professional schools, or other professionals, to help address the multidimensional problems faced by clients. It is a "multidisciplinary model [that] can respond to the myriad needs of those who are poor or marginalized by their social, medical or psychological circumstances." 13

10 See, e.g., Katherine C. Pearson and Lucy Johnston-Walsh, Partners in Outreach and Advocacy: Interdisciplinary Opportunities in University-Based Legal Clinics, 11 Journal of Higher Education Outreach and Engagement 163 (2006); Anita Weinberg and Carol Harding, Interdisciplinary Teaching and Collaboration in Higher Education: A Concept Whose Time Has Come, 14 Wash. U. J.L. \& Pol'y 15 (2004).

11 There is a long history of lawyers and social workers working together to serve low-income clients. In the early 1900s, lawyers and social workers discussed whether to join forces and, if so, how. One of the original models for the provision of legal services in the 1960s involved the placement of such a program within a multi-service social service agency, premised on a belief that legal services could be part of an anti-poverty program. Since the beginning of the legal services movement in the 1960's, lawyers and social workers have worked together to address the legal needs of their clients. See, e.g., Paula Galowitz, Collaboration Between Lawyers and Social Workers: Re-Examining the Nature and Potential of the Relationship, 67 Fordham L. Rev. 2123, 2130-31 (1999).

12 The terms "interdisciplinary" and "multidisciplinary" are sometimes used interchangeably but they have different meanings. "Multidisciplinary" implies that each discipline approaches issues from its own perspective, staying in its own "silo," more akin to separate but equal, while "interdisciplinary" implies a more integrated teaming among disciplines. See R. L. Jessup, Interdisciplinary versus multidisciplinary care teams: do we understand the difference?, 31 Australian Health Review 330-31 (2007).

13 Stacy L. Brustin, Legal Services Provision Through Multidisciplinary Practice-Encouraging Holistic Advocacy While Protecting Ethical Interests, 73 U. Colo. L. Rev. 787, 792 (2002), cited in Ezer et al., supra note 3, at 27. 
There are a number of reasons for the growth of interdisciplinary clinics. One is the crisis in many countries about the lack of availability of legal services in civil matters for indigent populations, leading to the need for new and innovative ways to deliver legal services. Another is the growing recognition that legal problems arise in larger contexts that require additional services and the clients' issues are not typically only legal in nature. ${ }^{14}$ Many clients have issues in which it can be difficult to separate the legal aspect from that which is typically associated with other disciplines. ${ }^{15}$ Professionals are increasingly aware that working together with other professions can better serve clients and improve outcomes. ${ }^{16}$ Leveraging limited resources can result in improved service for clients, where the professions working together can address problems more effectively than could be done by the professions working separately. ${ }^{17}$ In addition, there needs to be a "more conscious coordination and integration of delivery of services" to low-income communities. ${ }^{18}$ Non-lawyers can be important participants and actors in legal institutions ${ }^{19}$ and can help facilitate the interactions between the lawyer and the client.

\section{Attributes and Models of Interdisciplinary Clinics}

Certain attributes typify interdisciplinary clinics in which there are integrated interdisciplinary teams. ${ }^{20}$ One is a shared expertise, so that it is not legally focused and lawyer-directed. In this model it is not just the other professions assisting the lawyer, but rather the lawyer and other professional undertake a joint approach. In addition, the collaboration uses and relies on the knowledge of all of the participating disciplines. It is important that the various professionals understand that there are many ways that the law can be part of a comprehensive approach to meet the needs of the clients: litigation is not the only way. An additional component of interdisciplinary service is a team commitment to the importance of developing creative approaches to assist clients. Moreover, there should be a structure that formalizes the relationship

14 Multidisciplinary practices for low income and middle income clients recognize the "centrality of nonlegal as well as legal needs and the barriers clients face in accessing legal services." Louise G. Trubek and Jennifer J. Farnham, Social Justice Collaboratives: Multidisciplinary Practices for People, 7 Clinical L. Rev. 227,229 (2000). Some of the common elements in these collaboratives are shared expertise, the lawyer as both a professional and collaborator, and a long-range commitment to the client group. Id. at 257-63.

15 Mary Daly discussed this in the context of law and accounting and financial planning (Mary C. Daly, Choosing Wise Men Wisely: The Risks and Rewards of Purchasing Legal Services from Lawyers in a Multidisciplinary Partnership, 13 Geo. J. Legal Ethics 217, 222 [2000]), but it is even more applicable in the public interest arenas.

16 Multidisciplinary programs "offer a potentially significant advance in the way legal services are provided to lowincome and other marginalized programs." Brustin, supra note 13, at 794.

17 For a discussion of the effective leveraging of limited resources in medical-legal partnerships, see Randye Retkin, Julie Brandfield and Margo Hoppin, Medical-Legal Partnerships: A Key Strategy for Mitigating the Negative Health Impacts of the Recession, 22 The Health Lawyer 29 (October 2009).

18 Schlossberg, supra note 9 , at 210.

19 There is increasing recognition of "non-lawyers as important actors in legal institutions while simultaneously facilitating the engagement between lawyers and their clients." Id.

20 There are different models of interdisciplinary clinics. Three different models discussed in the literature are: 1) the "in-house" model in which clinical faculty include non-traditional legal skills such as community education and lobbying; 2) the "professional consulting/collaboration" model in which clinics use professionals from other disciplines on a consulting basis; and 3) an "integrated partnership model" in which professionals from different disciplines plan, develop and co-teach a clinic "to students from different disciplines who jointly provide legal and technical services to the clients of the clinic." Tokarz et al., supra note 1, at 382-384. Instead of falling clearly within only one of these models, some interdisciplinary clinics can operate on a continuum. Id. at 384 . 
between the professionals and anticipates the possible problem areas in joint service provision. ${ }^{21}$ Some of the interdisciplinary clinics also pursue approaches that foster systemic change.

Although true for all clinical education programs, it is particularly critical in interdisciplinary ones that the goals and values of the program are transparent and agreed upon by the various partners. For example, the success of the interdisciplinary program in Windsor, Canada depended on a shared understanding of its goals and values, curriculum design that reflected those goals and values, and institutional support and sanction for the goals and values. ${ }^{22}$ Effective interdisciplinary models "minimize the limitations imposed by differing professional roles, the pressures of time, the vagaries of personalities, and the imbalances in collaborative practice that are a reflection of existing power imbalances between the...professions in our culture."23

\section{Description of the Medical-Legal Advocacy Clinic at New York University School of Law: An Interdisciplinary Clinic}

The opportunities and challenges of an interdisciplinary clinic for students, clients and faculty teaching the clinic are discussed, using the model of and through the lens of a medical-legal interdisciplinary clinic that I co-teach. The Medical-Legal Advocacy Clinic at New York University School of Law (hereinafter MLAC) is a medical and legal collaboration. Most of these medicallegal collaborations in the United States are partnered with legal services offices; only a relatively small number are clinics based at law schools as part of an in-house clinic. ${ }^{24}$

The MLAC employs a multidisciplinary and holistic approach to provide legal advocacy in a medical setting for clients referred by medical professionals. Many legally-related issues can affect the health of low-income families and many of the problems that affect the health of the children and families have legal remedies. This clinic is a medical-legal collaboration to improve health outcomes for patients/clients by providing on-site legal advocacy and training to medical providers.

21 As stated by J. Michael Norwood and Alan Paterson in their description of a multidisciplinary practice in which the University of New Mexico Child Advocacy Clinic is the legal services provider, the professionals need to work out "an organizational structure that formalizes their relationship and addresses the complexities of responding to ongoing client needs in a manner that both maximizes efficiency of effort and minimizes ethical pitfalls." J. Michael Norwood and Alan Paterson, Problem-Solving in a Multi-Disciplinary Environment? Must Ethics Get in the Way of Holistic Services?, 9 Clinical R. Rev. 337, 357 (2002).

22 Voyvodic and Medcalf, supra note 9, at 102. This interdisciplinary clinic involving law students, social work students, lawyers and social workers had the following values: the joint effort of a university law school and government agency that links the clinic to professional education and engagement with social policy; service to low-income communities that shows a commitment to justice and social justice; an interdisciplinary approach that combines law with social work services; an inclusive range of services including casework, public legal education, community development and law reform activities; and a learning environment that suggests a balance between the academic curriculum and service to the community. Id. at 102-03.

23 Jacqueline St. Joan, Building Bridges, Building Walls: Collaboration Between Lawyers and Social Workers in a Domestic Violence Clinic and Issues of Client Confidentiality, 7 Clinical L. Rev. 403, 425 (2001). In this article, Professor St. Joan discusses collaboration between law students and social work students.

24 According to the website of the National Center for Medical-Legal Partnership, there are medical-legal partnerships at over 235 health institutions and, of those, fourteen are in law school clinics and sixteen, including two in Canada, are in law school externship programs. See http:/www.medical-legalpartnership.org/ mlp-network/law-schools (last visited May 17, 2012).

Jane R. Wettach discusses the model of a medical-legal partnership in a clinical setting, particularly one that focuses on education and government benefits. Jane. R. Wettach, The Law School Clinic as a Partner in a MedicalLegal Partnership, 75 Tenn. L. Rev. 305 (2008). 
In the first few years that the MLAC was taught, law students, who were in their second or third (last) year of law school, and pediatric medical residents (in the second and third year of a three year residency program after completing four years of medical school) collaborated to address more effectively the health issues of their clients/patients. The medical residents were in the Residency Program in Social Pediatrics at Montefiore Medical Center in New York City. These residents intend to practice in clinical practice, community health and advocacy; they spend a significant part of their clinical time in their second and third years of residency in a federally-funded community health center serving primarily low-income African-Americans and Latinos. The patients of the community health center present a multitude of psychosocial issues, including family disruption (due to illness, incarceration, violent injury, child abuse and/ or neglect), poor housing, unemployment and poverty, domestic violence, lack of access to health care, and immigration problems. Many legally-related issues can affect the health of the patients of the community health center, such as: asthma triggered by mold from leaky ceilings or rodent infestation; lead poisoning from paint not removed; burns caused by families heating apartments with stoves; and children who suffer due to insufficient nourishment. The patients of this community health center were referred by the medical residents to the law students for assistance.

The law students and the medical residents were trained together to practice an interdisciplinary and holistic approach to their patients/clients. The program was planned jointly by me and Iman Sharif, M.D., M.P.H., who was then Associate Director of Residency Training in Social Pediatrics and Associate Professor of Clinical Pediatrics at the Albert Einstein College of Medicine/ Children's Hospital at Montefiore Hospital. Dr. Sharif had initiated the collaboration; she had heard about medical-legal partnerships and wanted to start one with the social pediatric residents at the community health clinic as the medical partner. She contacted the clinical faculty at NYU School of Law and, as a result, I began working with her to plan the program. As part of developing the program, Dr. Sharif and I had to learn to collaborate, including understanding each other's language, culture, ethics, professional values, and approaches to our clients/patients.

In the clinic seminar, the law students and medical residents learned together. They met for eight two-hour joint seminars over the course of the law school semester, covering such topics as: collaboration and interdisciplinary work; ethics and confidentiality; asthma and environmental triggers; substantive law training on advocacy; early childhood education advocacy; lobbying training; holistic advocacy; and health law. The joint seminars were co-taught with Dr. Sharif. For each joint seminar, the law students and medical residents were given readings and learning objectives. Seminar speakers included practicing doctors, ethicists, lawyers, social workers, and leaders from child advocacy and legal advocacy.

The fieldwork had a three-fold approach: 1) direct client representation; 2) education of the medical residents and other health professionals about how to identify legal issues and incorporate advocacy into their treatment plans, as well as education of the clients/patients about their legal rights; and 3) identifying and exploring health care issues and presenting interdisciplinary strategies to address the issues. For the direct client representation, procedures were implemented to enable the medical residents and faculty at the outpatient community health center to refer patients to the law students for legal advocacy. Each week, law students provided a free legal clinic for clients referred by the medical residents. A joint electronic account was created to allow the doctors to schedule the legal appointments for their patients, after obtaining the consent of their patients. Legal assistance was provided on such areas as housing, government benefits, education and other 
issues that had an impact on the family's health. Before the fieldwork began, we discussed with the medical residents areas in which the law students could provide legal services and those that they could not (e.g., if the patient wanted to sue the doctor or needed representation in a lawsuit by the hospital for payment of a medical bill). Although we tried initially to limit our legal services to a few areas (to enable the law students to develop expertise in those areas), they were expanded to better serve the needs of the clients in a holistic manner. ${ }^{25}$

In addition to the joint seminar and the referral of cases, there were other parts of the collaboration. The law students developed policy projects by identifying and exploring health care issues and presenting interdisciplinary strategies to address those issues; students presented those policy projects at a joint seminar of the law students and medical residents. The law students and medical residents, after receiving joint training on how to lobby legislators, participated in an allday lobbying effort of state legislators at the New York State capital in Albany, New York on an issue affecting their patients/clients. At the beginning of the semester, the law students and medical residents together observed proceedings in Housing Court. In addition, there were a few informal gatherings outside of class to help build rapport and relationships.

\section{Opportunities}

There are many opportunities and advantages presented by interdisciplinary $\operatorname{clinics}^{26}$ : for the students and professionals involved in the collaboration; for the clients/patients who are better served; for the faculty who create and participate in the interdisciplinary clinic; for the professions and educational institutions; and for the pursuit of justice. ${ }^{27}$ “...[I]nterdisciplinary teaching and practice can promote collaboration, communication, cultural awareness, ethical understanding and justice." 28 These interdisciplinary clinics also address concerns about the narrowness of legal education and medical education raised in reports issued by the Carnegie Foundation for the Advancement of Teaching. ${ }^{29}$ The opportunities in this section are subdivided into those applicable to students, clients and faculty; many of these opportunities apply to more than one of these categories.

25 As discussed in Section V (C), one of the challenges for the clinic was getting the students ready to represent clients in a variety of subject areas.

26 Some of the opportunities and challenges in interdisciplinary projects and classes are also applicable to interdisciplinary clinics. For very helpful discussions of the benefits and barriers to interdisciplinary law school courses, see Kim Diana Connolly, Elucidating the Elephant: Interdisciplinary Law School Classes, 11 Wash. U. J.L. \& Pol'y 11 (2003) and Janet Weinstein, Coming of Age: Recognizing the Importance of Interdisciplinary Education in Law Practice, 74 Wash. L. Rev. 319 (1999). For a discussion of an interdisciplinary training program for law students and emergency medicine residents on domestic violence, see Antoinette Sedillo López et al., A Medical/Legal Teaching and Assessment Collaboration on Domestic Violence; Assessment Using Standardized Patients/ Standardized Clients, 14 IJCLE 61 (July 2009).

27 For other articles that discuss some of the advantages and disadvantages of interdisciplinary clinics, see, e.g., Luppino, supra note 8, at 163-179, 201-218; Jones, supra note 7, at 309-313; Voyvodic and Medcalf, supra note 9, at 116-27; Schlossberg, supra note 9, at 199-206. 212-226.

28 Tokarz, supra note 9 , at 3.

29 William M. Sullivan et al. Carnegie Foundation for the Advancement of Teaching, EDUCATING LAWYERS: PREPARATION FOR THE PROFESSION OF LAW (2007); Molly Cooke et al, Carnegie Foundation for the Advancement of Teaching, EDUCATING PHYSICIANS: A CALL FOR REFORM OF MEDICAL SCHOOL AND RESIDENCY (2010). 


\section{A. For Students}

While there are many advantages for students in interdisciplinary clinics, there are six categories that I think are the most important. The first, and in some ways the most important, is the broadening of perspectives. ${ }^{30}$ The law students and medical residents learned from each other and appreciated the differing professional cultures and skills as well as the problem-solving approaches of the other profession. ${ }^{31}$ As described by Professor Connelly:

Legal problems are like elephants; examining them from only one perspective gives a distorted image of the whole. In order to understand legal problems, lawyers often need to examine them from the perspective of multiple disciplines. Likewise, successful legal problem-solving sometimes means that lawyers need to be able to collaborate with other professional in order to address a client's problems. ${ }^{32}$

The law students and medical residents began to understand what they had in common and not just what separated them. They learned about the roles, boundaries and limits of each member of the collaboration, as well as a familiarity with the knowledge base of the other profession. We specifically discussed some of the similarities in the two professions, including the shared set of core social and ethical values (including shared respect for the individual, the commitment to reason, and using experience as a basis for decision-making); valuing of professional autonomy and decision-making; the primacy of serving their patient's/client's interests; the fiduciary obligation each owes to their patient/client; and the aspiration of each profession to provide services to the poor. To highlight the similarities, we also used an exercise ${ }^{33}$ in which the law students and medical residents wrote anonymously on color-coded cards (so that we could know whether the cards were completed by a law student or a medical resident) the attributes of a "good" lawyer; the attributes of a "good" doctor; the attributes of a "bad" lawyer; and the attributes of a "bad" doctor. The results of these cards were written on the blackboard so that all could see the responses; the similarities in the positive attributes for the two professions were surprising to many of the students and helped to emphasize the commonalities between the two professions. ${ }^{34}$

This broadening of perspective can lead to what is described as a higher level of cognitive

30 The broadening of perspectives in interdisciplinary clinics has been noted by many commentators in a variety of different types of interdisciplinary clinics. See, e.g., Ezer et al., supra note 3, at 32. Interdisciplinary clinics "offer many opportunities for the acquisition of valuable skills by means of collaboration with and exposure to the culture, professional strengths, and limitations of other disciplines in a group setting." Margaret Martin Barry et al., Clinical Education for This Millennium: The Third Wave, 7 Clinical L. Rev. 1, 69 (2000).

31 "With these diverse cultures and problem-solving approaches, collaboration between these professionals [lawyer, doctor, social worker and other professionals in a medical-legal collaboration] results in a formidable team that provides holistic interventions." Marcia M. Boumil, Debbie F. Freitas and Cristina F. Freitas, Multidisciplinary Representation of Patients: The Potential for Ethical Issues and Professional Duty Conflicts in the Medical-Legal Partnership Model, 13 J. Health Care L. \& Pol'y 107, 123 (2010).

32 Connolly, supra note 26, at 13-14.

33 This exercise was developed by Dr. Marc Schwartz and myself for a class that we co-taught for law students and medical students at New York University; the name of the course was "Doctor-Patient, Lawyer-Client: The Nature of Professional Relationships."

34 Some of the positive traits of both professions were empathetic, compassionate, good listener, ethical, caring, and zealous advocate. The results of the card exercise are on file with the author. 
processing, what some psychologists define as "wisdom." 35 Particularly for the law students, they learned the skills and values to function in a variety of forums (i.e., not just litigation) and learned skills and approaches from the other disciplines. ${ }^{36}$ It helped the law students and medical residents to move away from the narrow approach of seeing the patient's/client's issues as only medical or legal ones; it helped remove the "blinders" and minimize the "silo" effect. They also began to appreciate the shared professional values ${ }^{37}$ and more broadly viewing medical and legal problems in their larger social context. ${ }^{38}$ As stated by one of the medical residents, this interdisciplinary clinic:

provided the invaluable opportunity of learning from each other. As doctors and lawyers we seldom get the chance to gain knowledge and insight into each other's fields and professions. Most importantly, the legal clinic provided the unique and excellent venue to be able to serve as better advocates and lend a helping hand to our patients. In short, the experience gave both doctors and lawyers the ability to work together for change. ${ }^{39}$

To help facilitate the broadened perspective and ease into the collaboration, Dr. Sharif and I created case examples that were used in our first joint seminar. While the class discussion became animated (and heated), it was, upon reflection, critical to the success of our collaboration. As described by one of the medical residents:

The opening discussion that involved a case of potential child abuse was very revealing to me. I have been so engrossed in the medical world for so long, that their [law student's] opinions and approach were really shocking at first. But in the end, it was a great opportunity to appreciate the complexities of such situations. ${ }^{40}$

35 "It is this higher level of cognitive processing - what some psychologists define as 'wisdom' - that we see as the ultimate outcome of interdisciplinary higher education." Weinberg and Harding, supra note 10, at 23.

36 For example, in the interdisciplinary program in South Africa of integrating palliative care, the law students were trained in facilitation skills in order to be able to run the workshops for hospice caregivers. Ezer et al., supra note 3 , at 29.

37 An article about an interdisciplinary course for law students and medical students discusses discovering the shared goals and values in the two professions as part of the process of designing the course. "The similarities in our professions gave us faith that, despite our differences, we could create something special - a learning experience for law and medical students that would not only bring a different discipline into their classroom, but also could help them to re-envision their roles and responsibilities as professionals." Elizabeth Tobin Tyler, Teaching Social Justice and Health: Professionalism, Ethics and Problem-Solving in the Medical-Legal Classroom, 38 J.L. Med. \& Ethics 701, 702 (Fall, 2010).

38 Interdisciplinary collaborations "challenge students to consider medical and legal problems in their social contexts as well as to broaden their concepts of their professional roles and limits." Elizabeth Tobin Tyler, Allies Not Adversaries: Teaching Collaboration to the Next Generation of Doctors and Lawyers to Address Social Inequality, 11 Journal of Health Care Law \& Policy 249, 275 (2008).

39 Quotations of the medical residents and law students cited in this article were from reflection papers submitted by the law students, from written comments, and from surveys of the medical residents and law students that were completed in the first joint class and in the last joint class to evaluate the collaboration. The reflection papers, surveys and other written comments are on file with the author or Dr. Iman Sharif, the co-teacher of the seminar.

40 Id. 
The law students spoke of their loyalty to their client, who was the parent, and felt bound by the duty of confidentiality to their client to not reveal to the doctors what the client had told them about what the doctors might consider potential child neglect by the parent who was not the client of the lawyers.$^{41}$ The doctors discussed their responsibility to the entire family and were initially disturbed by what they saw as a narrow focus of the law students of preserving the confidentiality of the mother (the lawyer's client) over the possible health needs of the child and risk to the child. The law students explored the possible conversation with the client about consequences and possible actions which helped the residents understand more of the nature and parameters of the lawyer-client relationship. The discussion in that first class became a bonding experience for all, and one referenced in many other of our joint sessions as a mirror to help each of the professions appreciate the other.

The second benefit is that it helps to build trust, understanding and respect amongst the members. ${ }^{42}$ The third is that it teaches the importance of collaboration. ${ }^{43}$ The law students and medical residents in our joint seminars were taught skills to help them collaborate successfully. ${ }^{44}$ In the joint seminar, we first discussed their own experiences in collaboration, including what they had found to be helpful in successful collaborations and what had been problematic. We also highlighted, based on assigned readings ${ }^{45}$ and their comments in the class discussion, some things that can be done to improve collaboration, including the value of listening and effective communication; understanding and appreciating the "other," including the competencies of each profession; clearly stated role expectations; attitudes of respect and openness; learning skills for shared decision-making; and the importance of setting boundaries at the outset of the collaboration. (For our collaboration, one particular boundary issue was differing approaches to confidentiality and how it could limit what client/patient information could be shared between the

41 In New York, as in most states in the United States, lawyers are not mandated to report suspected child abuse and neglect while doctors are mandated reporters. For a discussion of the challenges posed by the differing mandated reporting requirements of lawyers and doctors, see, e.g., Boumil et al., supra note 31, at 124-127; Anderson et al., supra note 9.

42 In a multi-disciplinary program in which the Child Advocacy Clinic at the University of New Mexico is the legal partner, a curriculum was developed and implemented to build trust amongst the various team members. See Norwood and Paterson, supra note 21, at 363-64. This clinic is part of a multi-disciplinary program that includes law students, pediatricians, social workers, child development specialists, psychiatrists, case managers, nurses, program administrators, community planners, program evaluators and educational technology experts. Id. at 356.

43 "In order to creatively solve problems, attorneys must focus not only on a client's legal issues, but also the client's needs that can best be met through professional interdisciplinary collaboration. To be effective as creative problem solvers, students must learn the art and skill of collaboration. However, most law school curricula, including clinical courses, do not recognize the value of collaboration as a skill for problem solving, and therefore do not emphasize it in their teaching." Schlossberg, supra note 9, at 203.

44 Janet Weinstein, in an article on interdisciplinary education in law practice, identifies five skills for effective collaboration: communication skills; knowledge of non-legal resources; awareness of self and others; an understanding of and appreciation for group process; and leadership skills. Janet Weinstein, Coming of Age: Recognizing the Importance of Interdisciplinary Education in Law Practice, 74 Wash. L. Rev. 319, 335-40 (1999).

45 See Sue Bryant, Collaboration in a Law Practice: A Satisfying and Productive Process for a Diverse Profession, 17 Vermont Law Review 459 (1992-1993). 
doctor and lawyer. $)^{46}$

The fourth advantage of an interdisciplinary clinic is what I call a "window." It is a window in two very different ways. One is that it can help students prepare for the "real world" by modeling the experience of practicing law, which increasingly uses interdisciplinary collaborations. The other, and what I think is more important and unique to interdisciplinary clinics, is that it can cause law students to reconsider their own roles as lawyers and advocates. Also, it helps each of the professions form (and change) their views of their own profession and their roles within it.

The fifth point is that the collaboration can be a more satisfying and fulfilling professional and personal experience for all. The sharing of experiences and approaches to assist clients/patients can result in increased satisfaction. It can also result in increased comfort in being able to learn from and rely on the other professionals. Collaboration can help reduce the stress that lawyers can experience. ${ }^{47}$ From their comments in class as well as their written reflections, it was apparent that it was a more fulfilling model for each of the professions involved. A typical comment by one of the medical residents was that the collaboration "provided the invaluable opportunity of learning from each other.... This experience gave both doctors and lawyers the ability to work together for change." 48 Connected to the collaboration amongst the students and residents, there was also collaboration between the faculty teaching the seminar, with the faculty modeling for the students and medical residents.

Finally, interdisciplinary clinics offer more creative and better service for the clients. ${ }^{49}$ It can result in the professionals being engaged in more creative problem-solving to promote justice. ${ }^{50}$ Collaboration empowers the professionals to serve their clients/patients in new and better ways. As stated by one of the medical residents in the clinic, it "helped me to realize that the things we learn about our patients are often limited by what we are willing to explore and the resources that we have at our disposal." 51

\section{B. Opportunities for Clients}

One of the most important advantages of interdisciplinary clinics is improved service for the

46 For a detailed discussion of various ethical issues in a collaboration between lawyers and doctors, see Paula Galowitz, Jerome Tichner, Paul R. Tremblay and Steven D. Blatt, Ethical Issues in Medical-Legal Partnership (Chapter Six), in POVERTY, HEALTH AND LAW: READINGS AND CASES FOR MEDICAL-LEGAL PARTNERSHIP (Elizabeth Tobin Tyler, Ellen Lawton, Kathleen Conroy, Megan Sandel, and Barry Zuckerman eds., Carolina Academic Press, 2011).

47 See Galowitz, supra note 11, at 2128.

48 See note 39, supra, for a discussion of the comments of the law students and medical residents.

49 "An interdisciplinary model also has the potential to encourage lawyers to create innovative programs that not only respond to the perceived needs of client communities but also actively involve clients in bringing about social change." Brustin, supra note 13, at 794.

50 In her article on interdisciplinary education in law practice, Janet Weinstein discusses five skills needed for collaborative problem solving: communication skills; knowledge of non-legal resources; awareness of self and others; an understanding of and an appreciation for group process; and leadership skills. Weinstein, supra note 26, at 335-341. Some of the professions involved in interdisciplinary collaborations, such as social work, teach these skills in professional school. See Voyvodic and Medcalf, supra note 9, at 123.

51 See note 39, supra, for a discussion of the comments of the law students and medical residents. 
clients. ${ }^{52}$ The complementary skills of the other professions can help the lawyer serve the client, ${ }^{53}$ as can the legal information assist the doctor to be a better medical provider and advocate for his or her patients. For example, the medical residents became more familiar with laws affecting their clients (such as educational services for children with special health care needs and eligibility for disability programs) and developed practical skills for advocating for their patients to receive the services to which they were entitled. They also felt more knowledgeable and comfortable exploring with their patients how the realities of their patients' lives (such as housing conditions) impacted on their health. For the law students, they understood the medical conditions that could impact on their clients' disabilities and were able to use that information to argue more persuasively for the benefits for which their clients were eligible.

As discussed in the previous section on opportunities for the students, law students are helped to move from the narrow approach of seeing the client's "issues" as only legal ones and all of the students and professionals are better trained to see the clients/patients in a more holistic way, understanding the roles that each profession can bring to help identify the legal and social barriers that affect the health of their clients/patients and that impact on the social issues underlying inequalities in health. As noted by one of the law students, the clinic was "helpful in exposing me to different ways that doctors and lawyers can collaborate to make inroads to achieving health outcomes for vulnerable populations...[and] ensure that laws that promote health and safety are being enacted and followed." ${ }^{54}$ Moreover, in the MLAC, it seemed to be easier for the clients to establish relationships with the law students since someone with whom the client already had a relationship made the connection to the law student. Research about the impact of interdisciplinary collaborations on clients would reveal if there are other benefits for them.

\section{Opportunities for Faculty}

Teaching in an interdisciplinary structure has benefits that parallel those for the students described in Section IV (A): it can broaden the perspectives of all of the participants so that each of the professionals has a better understanding of the other's attitudes and values, approaches to problem solving, language, and ethical constraints; help build trust, understanding and respect amongst the members; provide a "window;" result in better and more creative services for the clients; and can be more personally satisfying. Teaching in an interdisciplinary structure also has unique additional advantages for the faculty. One is that it helps emphasize the importance of teaching creative problem-solving and collaboration. In the seminar and in the fieldwork, the students can be helped to see the issues that the client faces in the broader context of the client's life and the students can be helped "to think about prevention of future problems, not just solving current ones." 55 It also helps the faculty to expand the approaches to assist students' learning through collaboration with other disciplines.

52 Doctors and lawyers working together can improve the health outcomes for the patients/clients. See, e.g., Boumil et al., supra note 31 , at 137 .

53 "A multidisciplinary approach provides an ideal way to address complex social issues such as domestic violence, concerns facing the elderly, community economic development, and poverty more generally. Professionals from different disciplines can use their skills to develop more comprehensive solutions for clients." Brustin, supra note 13 , at 794 .

54 See note 39, supra, for a discussion of the comments of the law students and medical residents.

55 See Tobin, supra note 38, at 275. 
I personally found that the collaboration with Dr. Sharif in our development and plans for the seminar and fieldwork, as well as in co-teaching the seminar, resulted in unexpected beneficial results. We initially had to explore and try to understand our different professional values and norms, including language and approaches to issues. Fortunately we had given ourselves time to develop our relationship and plan for the challenging issues; we started our planning approximately a year before the clinic began. Not only did we need to plan for our law students and medical residents but we also had to plan for our own collaboration and co-teaching. We openly talked with the law students and medical residents about this interdisciplinary experience as being new and approaching things together as we sorted out the opportunities and challenges. This had the effect of freeing us all to be more open and transparent. For me personally, this transparency and the creativity in designing and implementing this interdisciplinary clinic resulted in a much more satisfying teaching experience.

\section{Challenges}

There are many challenges in designing and implementing an interdisciplinary clinic. ${ }^{56}$ However, there are ways to minimize the challenges and enhance the opportunities. One important way is to spend sufficient time with the other professionals in planning the clinic and the program. Many of the challenges can be anticipated and addressed before the clinic officially begins. The design of the program can help implement successful collaborations. "Interdisciplinarity ....is not a 'magic bullet'...; collaboration must be taught as a skill, and the needs of the individuals who will be collaborating must be anticipated and met with information and appropriate training." 57 The challenges in this section are subdivided into those applicable to students, clients and faculty; many of these challenges apply to more than one of these categories.

\section{A. Challenges for Students}

While there are many challenges in interdisciplinary clinics, there are five categories that I think are the most significant. The first (and an especially pervasive) one was the differences in the language, customs, and norms of the collaborating professions. Each needed to learn and appreciate the other. Since Dr. Sharif and I understood this to be key to the success of the collaboration, we each spent time discussing this in our individual seminar sessions before we started our joint one and addressed this directly in our first joint class. Dr. Sharif and I developed the case examples described in Section IV(A) to highlight these issues.

The second category is that of ethical obligations and professional values. There are differences in ethical obligations such as confidentiality, conflicts of interest and the professional independence of the lawyer that must be addressed. While dealing with them can be challenging, they are not barriers, particularly if the anticipated issues are discussed and addressed amongst the various professionals when forming the collaboration. ${ }^{58}$ Guidelines and protocols for the anticipated ethical issues (such as what information received from the client can be shared with the other

56 Barriers to interdisciplinary work include the lack of skills training; the narrow and competitive nature of legal education and practice; different professional cultures; and personality issues in law students and lawyers that can interfere with collaboration. See Weinstein, supra note 26, at 328-351.

57 Voyvodic and Medcalf, supra note 9, at 116.

58 See Galowitz et al., supra note 46. 
professionals) should be drafted together as part of the development plan.

The third area is student discomfort and anxiety. It can be very challenging for law students in any clinic to learn about and become comfortable with a range of skills and substantive areas of the law. Any discomfort and possible anxiety can be compounded by working with other professions when the students may be unsure of their own professional roles and values. ${ }^{59}$ To minimize this discomfort, Dr. Sharif and I found it very helpful to have an informal gathering early in the semester for the law students and medical residents to get to know each other. In addition, a curriculum with hypothetical examples can be created to help build trust and understanding amongst the various professions and members of the interdisciplinary clinic. ${ }^{60}$

Fourth, the nature of the professional norms in law school can create challenges. Law students tend to be more competitive (which would also make it more difficult for them to collaborate) ${ }^{61}$ and that they have less experience in collaboration than other professions (such as students in business school). ${ }^{62}$ Collaboration as an important skill and value for professionals needs to be directly addressed. In the MLAC, as mentioned in Section IV (A), we discussed collaboration in a joint seminar, including what interferes with collaboration and what can be done to improve our abilities to collaborate.

Finally, there are many logistical and situational challenges in an interdisciplinary clinic. ${ }^{63}$ For example, the law school schedule and the definition of a semester differ substantially from medical schools and residency training programs.. Another challenge is that collaboration and interdisciplinary work can take longer and therefore appear to be less efficient.

\section{B. Challenges for Clients}

For the clients, there can be confusion about the roles and approaches of the various professions. The client may not be sure which issues should be addressed with which professional. In addition, there may not be consistent information or opinions conveyed to the client by the various professionals who are interacting with the client. The client may also have unclear expectations. Research about the impact of interdisciplinary collaborations on the clients would reveal any other drawbacks.

\section{Challenges for Faculty}

Teaching in an interdisciplinary clinic has challenges that parallel those for the students described in Section V (A), including differences in language, customs and norms of the profession; ethical

59 Some law students may display resistance and discomfort with collaboration. See Voyvodic and Medcalf, supra note 9 , at 121-23.

60 Various strategies to build and enhance the interdisciplinary relationship are discussed in the article by J. Michael Norwood and Alan Paterson including: learning from each other to understand and appreciate the diversity of professional cultures and problem-solving approaches of the members of the team; learn and understand the roles, boundaries and limits of each member of the team as they relate to the purposes of the multi-disciplinary project; and create a formal curriculum in order to build understanding and trust amongst the members of the team. Norwood and Paterson, supra note 21, at 362-366.

61 See Weinstein, supra note 26, at 340-44.

62 See Schlossberg, supra note 9, at 216-19.

63 Some of these logistical and situational challenges are discussed in Section V (C), Challenges for Faculty, infra. See also, Luppino, supra note 8, at 201-16. 
obligations and professional values; discomfort and anxiety; the nature of the professional norms in the law school; and logistical and situational issues. It can be difficult and uncomfortable to step out of one's comfort zone. ${ }^{64}$ Each profession has its own emphasis on independence of professional judgment. ${ }^{65}$ Each (including faculty and students) needs to learn to understand and appreciate the other.

The ethical requirements of each of the professions need to be addressed, ${ }^{66}$ particularly the varying definitions of who is the "client," confidentiality, conflicts and capacity of the person to make decisions. Scholarship has addressed ways to deal with the confidentiality requirements of the various professions in interdisciplinary collaborations, particularly the confidentiality requirements of lawyers, by obtaining informed consent from the client ${ }^{67}$ or creating a confidentiality "wall" so that there are boundaries between the professions relating to access to certain client information. ${ }^{68}$ As with many other challenges, ethical and professional value issues can be anticipated and dealt with in the design and planning of the curriculum, including developing protocols to address them. ${ }^{69}$

As to the assumptions that may be made about the "other" professions in the collaboration (with some of those assumptions being negative stereotypes), it can be helpful to surface them in a nonthreatening way. One example is the exercise described in Section IV (A) in which we asked each student to write the positive attributes of lawyers and doctors as well as negative characteristics of each of the professions. We then discussed those attributes and characteristics and helped surface their assumptions in a non-threatening format.

There may also be different pedagogical goals for the students and different learning experiences in the relevant professional schools. One example is that law school emphasizes getting law students to think like a lawyer compared with a business school focus on problem solving. ${ }^{70}$

An issue that I found particularly difficult was getting the law students ready to be "lawyers" in many different kinds of subjects, approaches and practice. While getting students comfortable in a variety of subject areas can be a challenge in any clinic that practices holistic advocacy, it can be more difficult in an interdisciplinary clinic since the students need some knowledge about the

64 "Collaborative interdisciplinary medical-legal teaching, like professional practice is challenging. There is no question that there are times when sticking to one's comfort zone and chosen field would be much easier." Tobin, supra note 37 , at 705-06.

65 "Independence of professional judgment is the hallmark of a profession, regardless of whether that profession is medicine, social work, or law. When professionals who are educated and trained differently, practice different trades, and follow different ethical codes combine efforts to provide one holistic remedy, each may be required to compromise some of the professional autonomy that each practitioner typically exercises." See, e.g., Boumil et al., supra note 31 , at 123 .

66 Some of the ethical issues and professional conflicts in medical-legal collaborations is discussed in the scholarship. See, e.g., Boumil et al., supra note 31; Norwood and Paterson, supra note 21; Galowitz et al, supra note 46 .

67 See, e.g., Galowitz et al., supra note 46.

68 See. e.g., St. Joan, supra note 23.

69 It has been suggested that there need to be changes in each of the relevant professions to support interprofessional collaboration; there should be an explicit standard in each of the profession's standards or codes of conduct that support interprofessional collaboration. Linda Morton, Howard Taras and Vivian Reznick, Encouraging Physician-Attorney Collaboration Through More Explicit Standards, 29 Hamline J. Pub. L. \& Pol'y 317 (2008).

70 See Jones, supra note 7, at 311-12. 
other profession or professions with whom they will be collaborating. There were two things that Dr. Sharif and I did in the MLAC to help address these challenges. The first was to front-load the clinic to spend the first few weeks discussing the substantive law areas and professional skills, including a simulation of a client interview for which the law students reflected and received feedback to prepare them before seeing their first clients. I was also at each of the fieldwork clinics when the law students interviewed their clients so that they could check-in with me before the interview was completed. This ensured that critical issues, such as deadlines and statute of limitations, weren't missed.

There are several logistical and institutional challenges in an interdisciplinary clinic, such as: scheduling of joint classes that are convenient for each of the professions; different academic calendars; defining the criteria for the credits and grades (if graded); and the allocation of tuition between or among the relevant schools. ${ }^{71}$ These issues need to be anticipated as much as possible and dealt with as part of the planning. As more interdisciplinary programs are created, it should become easier for the institutional challenges to be addressed.

Not surprisingly, it takes more time and energy for the faculty to develop and teach an interdisciplinary clinic than one that is not interdisciplinary. There is also a steep learning curve for the faculty and for everyone involved in the clinic. While the learning curve is included in the section on challenges, it also is part of the opportunities of such a clinic, and can lead to exciting ways to teach, learn and provide services for clients.

\section{Conclusion}

An interdisciplinary clinic has many different advantages for the students, faculty, professionals, clients and the professional schools. While there are challenges for all involved, they are far outweighed by the multiple benefits. I have found that all, including myself, were enriched by the interaction with our medical colleagues. The clinic also helped model for the law students and medical residents the value of interdisciplinary approaches to help meet the needs of our clients/ patients. Interdisciplinary clinics can "help develop a cadre of future lawyers with the sensitivity and expertise to play a leading role in addressing complex health and human rights issues."72 As stated by one of the medical residents in the clinic, it

provided the invaluable opportunity of learning from each other. As doctors or lawyers we seldom get the change to gain knowledge and insight from each other's fields and profession. Most importantly, the legal clinic provided the unique and excellent venue to be able to serve as better advocates and lend a helping hand to our patients. In short, this experience gave both doctors and lawyers the ability to work together for change. ${ }^{73}$

For me, it is a very exciting way to teach, for students to learn, for clients to be served, and to help all of the participants reflect on the role of law and being a professional.

71 For a discussion of additional challenges, see, e.g, Jones, supra note 6, at $310-313$ (discussion of administrative/ financial impediments, cultural and ethical impediments); Luppino, supra note 8, at 206-215 (issues include managing and addressing student expectations, and helping the professional teams work together).

72 Ezer et al., supra note 3, at 33.

73 See note 39, supra, for a discussion of the comments of the law students and medical residents. 